\title{
АНОМАЛЬНА ПРОВІДНІСТЬ У МОНОКРИСТАЛАХ СЕЛЕНІДУ ЦИНКУ ПІД РЕНТІЕНІВСЬКИМ ОПРОМІНЕННЯМ
}

\author{
В.Я. ДЕГОДА, ${ }^{1}$ В.Т. ВЕСНА, ${ }^{1}$ Б.В. КОЖУШКО, ${ }^{2}$ Г.П. ПОДУСТ ${ }^{1}$ \\ ${ }^{1}$ Київський національний університет ім. Тараса Шевченка, фізичний факультет \\ (Просп. Академіка Глушкова, 4, Київ 03022; e-mail: degoda@ univ. kiev. ua) \\ ${ }^{2}$ Інститут фізики НАН України \\ (Просп. Науки 46, Київ, 03028, Украӥна; e-mail: bkozhush@iop. kiev. ua)
}

\begin{abstract}
Експериментально досліджено здатність монокристалів селеніду цинку забезпечити роботу напівпровідникового детектора в режимі прямого перетворення енергї йонізуючого випромінювання на електричний сигнал. Встановлено, що для зразка ZnSe $n$ типу $\left(E_{d}=0,26 \mathrm{eB}\right)$ з питомим опором $\rho \sim 10^{9}$ Ом·см за кімнатної температури спостерігається зменшення провідності під дією рентгенівського опромінення, на відміну від високоомних монокристалів з $\rho>10^{12}$ Ом·см. Виявлено, що вольт-амперна характеристика (BAX) таких зразків для темнової провідності вища за ВАX рентгенопровідності, при цьому форми цих кривих помітно відрізняються. Очевидно, що характер рентгенопровідності ZnSe, за якої генеруються вільні носії обох знаків, суттєво відрізняється від характеру темнової провідності, коли в зразку є лише вільні електрони. Відповідно, для струму рентгенопровідності одержано спадаючу люкс-амперну характеристику (ЛАХ). Досі згадок про таку нетипову поведінку зазначених вище фізичних величин і характеристик у науково-технічній літературі не було. Це аномальне явище може бути зумовлене неоднорідною перезарядкою глибоких центрів біля електричних контактів і, відповідно, появою об'ємних зарядів, які зменшують рентгенопровідність монокристалічного $\mathrm{ZnSe}$.
\end{abstract}

\section{1. Вступ}

Селенід цинку (ZnSe) належить до найперспективніших широкозонних матеріалів типу $A^{2} B^{6}$ і досить добре вивчений [1-3]. ZnSe має широкі застосування в створенні приладів напівпровідникової електроніки і систем відображення інформації [4]. Нині відомо, що з полікристалічного селеніду цинку виготовляють оптичні лінзи, вікна, призми, дзеркала і т. ін., які здатні працювати у видимій та інфрачервоній ділянках спектра (0,55-22 мкм) як у спеціальних оптичних системах, так і $\mathrm{CO}_{2}$-лазерах.

За останне десятиріччя розвинено ще один перспективний напрям застосування ZnSe (монокристалічного), пов'язаний з його використанням у детекторах йонізуючого випромінювання непрямого (сцинти- лятори) [5] й прямого перетворення енергії високоенергетичних частинок в електричний струм [6, 7]. За сукупністю електрофізичних, фізико-хімічних, люмінесцентних властивостей і радіаційної стійкості селенід цинку, легований телуром - $\mathrm{ZnSe}(\mathrm{Te})$, є сьогодні одним з найефективніших сцинтиляторів для використання у детекторах типу “сцинтилятор-фотодіод" [5].

Використання нелегованного ZnSe як напівпровідникового детектора стало можливим лише після розвитку технологій вирощування досить якісних монокристалів з малими концентраціями неконтрольованих домішок і великим питомим опором матеріалу на рівні $\rho \sim 10^{10}$ Ом·см. Слід зазначити, що досить високе значення ефективного атомного номера $Z_{\text {ef }}=32$ й ширини забороненої зони $E_{g}=2,7$ еВ (при $300 \mathrm{~K}$ ) роблять селенід цинку перспективним матеріалом для створення рентгенівських детекторів, що не потребують охолодження [6]. Тому експериментальні дослідження рентгенопровідності монокристалів ZnSe за кімнатної температури стали для нас пріоритетним напрямом.

Також проводились дослідження кінетики рентґенолюмінесценції (РЛ) і рентгенопровідності (РП) за послідовного увімкнення рентгенівського опромінення й прикладання до електричних контактів напруги, і навпаки. Становило інтерес порівняння кривих розгоряння та згасання інтенсивності РЛ і струму РП в різних зразках ZnSe, а також порівняння їх 3 кінетикою розгоряння й згасання темнової провідності. Внаслідок проведення таких досліджень було отримано оригінальні результати, що становлять предмет цієї статті.

\section{2. Експеримент та отримані результати}

Досліджувалися люмінесценція і провідність монокристалічного ZnSe, під дією рентгенівських квантів. 


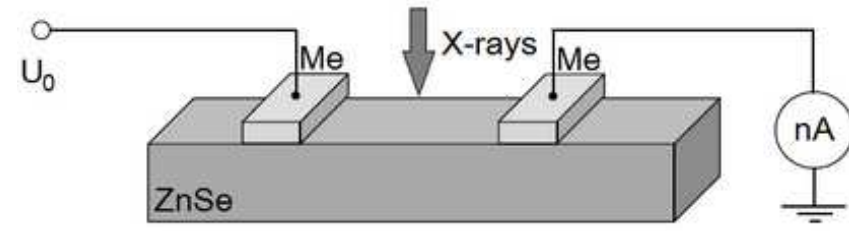

Рис. 1. Схема вимірювання рентгенопровідності

Кристали селеніду цинку вирощували з попередньо очищеної порошкуватої шихти й у процесі росту їх спеціально не легували. Ці заходи забезпечили можливість отримання зразків з мінімальною концентрацією точкових дефектів і максимальним питомим опором $\left(\rho \geq 10^{12}\right.$ Ом·см). Загальновідомо, що збільшення інтенсивності зовнішнього опромінення напівпровідникового кристала приводить до зростання в ньому кількості вільних носіїв заряду й, відповідно, струму провідності. Але проведені нами дослідження рентгенопровідності дали протилежний результат. Особливістю експерименту було те, що цю аномалію спостережено лише в зразках з порівняно невеликим питомим опором ( $\left.\rho \sim 10^{9} \mathrm{Oм} \cdot \mathrm{cm}\right)$, для яких темновий струм був у рази (а не на порядки) меншим від струму РП у високоомних зразках. Для дослідження провідності на поверхню кристалів резистивним методом напилювали металеві електричні контакти, до яких підпаювали мідні провідники. Відстань між електродами становила 5 мм. На один електрод подавали напругу $U_{0}$, інший через наноамперметр був заземлений. Дослідження струму провідності проводили у вакуумі $(P<1$ Па). Для всіх значень струму провідності виконувалася необхідна умова: вхідний імпеданс наноамперметра був на декілька порядків меншим за електричний опір зразка ZnSe. Схематичне зображення проведення експерименту й геометрію зразка показано на рис. 1. Оптична вісь системи реєстрації люмінесценції проходить посередині між електричними контактами.

Вимірювання проводили за кімнатної температури $(295 \mathrm{~K})$, збудження РЛ і РП здійснювалося інтегральним випроміненням рентгенівської трубки БХВ-7 (робочий режим: $\operatorname{Re}, 20 \mathrm{~KB}, 5-25 \mathrm{~mA}, L=120 \mathrm{мм}$ ) через берилієве вікно в кріостаті. Інтенсивність рентгенівського збудження змінювалася шляхом регулювання анодного струму рентгенівської трубки за сталої напруги. При цьому форма спектра випромінення трубки не змінювалась, а інтенсивність була пропорційна величині анодного струму трубки. Методом термоерс встановлено, що в дослідних зразках наявна провідність $n$-типу. 3 температурної залежності темнової провідності визначено глибину донорного рівня

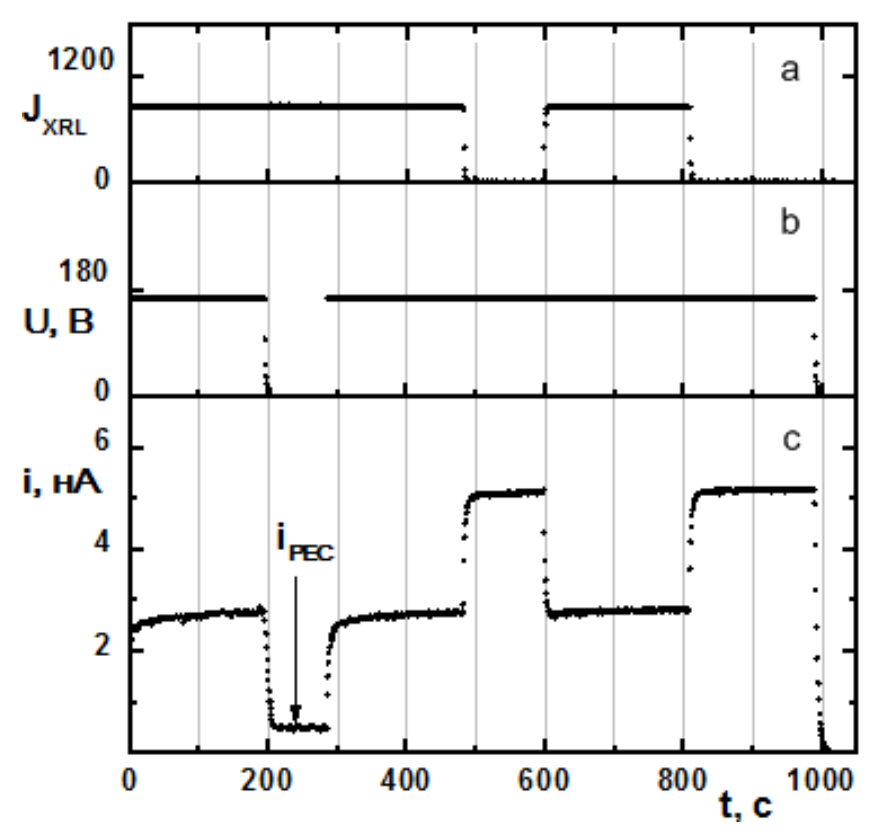

Рис. 2. Зміна з часом інтенсивності рентґенолюмінесценції смуги 630 нм $(a)$, прикладеної напруги $U_{0}=165 \mathrm{~B}(b)$ й струму провідності $(c)$ для зразка ZnSe за кімнатної температури

$E_{d}=0,26 \mathrm{eB}$, який забезпечує темнову провідність за кімнатної температури. Крім того, було виміряно BAX темнової й рентґенопровідності, а також люксамперні характеристики РП і РЛ. Домінантною смугою свічення в спектрі РЛ була добре відома червона смуга з максимумом на довжині хвилі 630 нм, спостережувана практично в усіх зразках селеніду цинку [4-7]. За допомогою реєстрації рентгенолюмінесценції здійснювався поточний контроль над опроміненням зразка. Як виявилося, для певних зразків монокристалічного ZnSe експериментально спостерігалося зменшення струму провідності під рентгенівським опроміненням i, водночас, мала місце інтенсивна рентґенолюмінесценція (рис. 2).

Кінетика зміни величини струму зі вмиканням/вимиканням напруги й рентґенівського опромінення за кілька десятків секунд зрівноважується й протягом наступних десятків хвилин не спостерігається жодних тенденцій до змін. Слід зазначити, що за рентґенівського опромінення зразка у вакуумі й напруги на контактах $U=0$ В спостерігається рентгеноемісійний струм $\left(i_{\text {рес }}\right)$, величина якого становить десятки пікоампер. Цей струм зумовлений емісією високоенергетичних електронів зі зразка під час поглинання рентгенівських квантів у приповерхневому шаpi. При цьому емітовані електрони потрапляють на заземлений корпус кріостата й через наноамперметр 


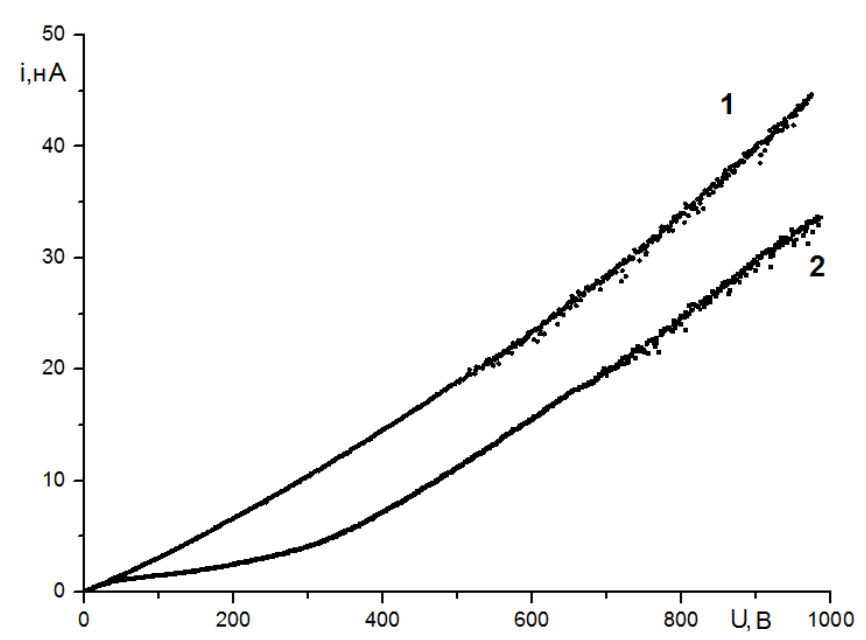

Рис. 3. Вольт-амперні залежності темнової (1) та рентгенопровідності (2) монокристалічного зразка ZnSe за кімнатної температури

повертаються до зразка ZnSe. Як видно з рис. 3, BAX темнової провідності перевищує ВАХ рентгенопровідності й має інший характер поведінки.

Звертаємо увагу на те, що за малих напруженостей зовнішнього електричного поля (до 100 В/см) струм РП практично не відрізняється від темнового струму, що може свідчити про малу зміну концентрації вільних носіїв заряду. Таке ж рентгенівське опромінення у високоомних кристалах ZnSe приводить до мікроамперних струмів, тобто, в цьому зразку маємо надзвичайно малий час життя носіїв у вільному стані і велику концентрацію донорів. А при полях більших за 500 В/см криві ВАХ практично паралельні зі сталим зміщенням 350 В/см. Це можна пояснити стаціонарною генерацією об'ємних зарядів біля електричних контактів зразка, які й створюють поле, направлене протилежно до прикладеного зовнішнього поля.

Одержані ЛАХ для РП і РЛ, наведені на рис. 4, узгоджуються з іншими наведеними в роботі результатами. Інтенсивність РЛ (смуга 3 максимумом на 630 нм) змінюється, як і очікувано, практично лінійно з інтенсивністю рентгенівського опромінення. При цьому струм РП монотонно спадає з інтенсивністю опромінення. Така залежність ЛАХ струму РП аномальна й не має пояснення в рамках класичної теорії фотопровідності. Як відомо, екпериментально завжди спостерігалося зростання провідності з концентрацією вільних носіїв або провідність не змінювалася (як в металах), якщо концентрації згенерованих вільних носіїв залишаються набагато меншими за темнові концентрації носіїв заряду.

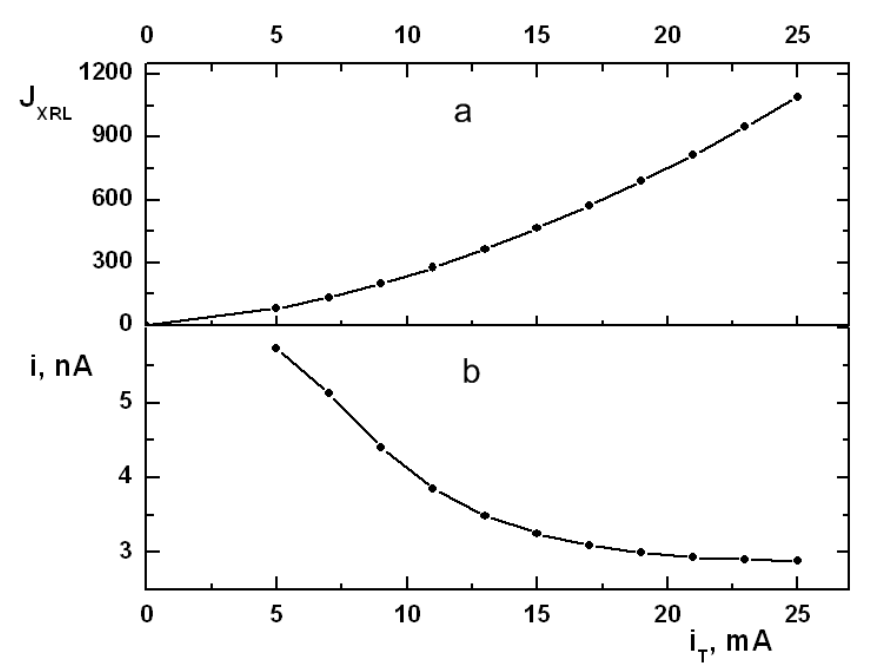

Рис. 4. Залежності інтенсивності РЛ ( $a$ ) й струму РП $(b)$ від інтенсивності рентгенівського опромінення (величини анодного струму рентгенівської трубки) при $U_{0}=165 \mathrm{~B}$

Зменшення провідності з ростом інтенсивності генерації носіїв заряду - аномалія, бо ймовірність поглинання рентґенівських квантів не залежить від їхньої кількості. Досі в літературних джерелах не було згадки щодо подібної аномальної поведінки провідності в широкозонних напівпровідникових монокристалах типу $A^{2} B^{6}$ за рентґенівського чи $\gamma$ опромінення. У той самий час, деякі дослідники отримували нелінійні ЛАХ фото- та рентгенопровідності [8-11].

\section{3. Висновки}

Таким чином, для монокристалічного ZnSe $n$-типу 3 певною величиною власної провідності (питомий опір $\rho \sim 10^{9}$ Ом·см) спостерігалася аномальна поведінка рентгенопровідності, а саме: за сталої напруги на контактах має місце різке зменшення струму провідності майже вдвічі під час рентгенівського опромінення. В той самий час у більш високоомних зразках такого ефекту не помічено. Встановлено, що ВАХ темнової провідності перевищує за величиною ВАХ рентгенопровідності. До того ж ВАХ темнової провідності майже лінійна, тоді як ВАХ рентгенопровідності помітно нелінійна. Тобто, на характер темнової та рентгенопровідності впливають різні фізичні процеси. Слабка нелінійність темнової провідності, напевно, зумовлена ефектом Пула-Френкеля [12]. Сильну нелінійність рентгенопровідності, коли генеруються вільні носії обох знаків, можна пов'язати з утворенням об'ємних зарядів у приконтактних ділянках 
зразка, що кардинально змінює результуючу величину електричного поля всередині кристала. Експериментально встановлено важливий факт: за певних величин параметрів монокристалічного селеніду цинку (наприклад, не досить високий питомий опір) відбувається зменшення провідності напівпровідникового матеріалу під дією рентґенівського опромінення, що рівнозначно падінню величини корисного сигналу від детектора. Щоб монокристалічний ZnSe був придатний для застосування в твердотільних детекторах прямого перетворення падаючого потоку йонізуючого випромінювання, слід використовувати лише високоомний матеріал з величиною питомого опору не меншою, ніж $10^{12}$ Ом.см.

Автори щиро вдячні академікові М.С. Бродину за плідне обговорення результатів роботи, їхню інтерпретацію й цінні зауваження.

1. А.Н. Георгобиани, М.К. Шейнкман, Физика соединений $A^{I I} B^{V I}$ (Наука, Москва, 1986).

2. В.И. Гавриленко, А.М. Грехов, Д.В. Корбутяк, Оптuческие свойства полупроводников (Справочник) (Наукова думка, Киев, 1987).

3. Д.Д. Недеогло, А.В. Симашкевич, Электрические и люминесцентные свойства селенида иинка (Штиинца, Кишинёв, 1984).

4. Н.К. Морозова, В.А. Кузнецов, В.Д. Рыжиков, Селенид иинка. Получение и оптические свойства (Наука, Москва, 1992).

5. Л.В. Атрощенко, С.Ф. Бурачас, Л.П. Гальчинецкий, Б.В. Гринев, В.Д. Рыжиков, Н.Г. Старжинский, Кристалль сиинтилляторов и детекторы ионизирующих излучений на их основе (Наукова думка, Киев, 1998).

6. М.С. Бродин, В.Я. Дегода, Б.В. Кожушко, А.О. Софієнко, Сенсорна електроніка і мікросистемні технології 2(8), № 4 (2011).

7. A.O. Sofienko, V.Ya. Degoda, Radiation Measurements 47, (2012).

8. В.Д. Куликов, Ю.В. Лисюк, ЖТФ 70, вып. 9 (2000).

9. С.Н. Мустафаева, М.М. Асадов, Д.Т. Гусейнов, ЖТФ 81, вып. 1 (2011).

10. А.Г. Гусейнов, В.М. Салманов, Р.М. Мамедов, ФТП 40, вып. 4 (2006).

11. В.В. Токий, В.И. Тимченко, В.А. Сорока, ФТТ 45, вып. 4 (2003).

12. В. Дегода, Г. Василенко, Вісник Київського нац. універ. ім. Т.Шевченка, Фізика, вип. 10-11 (2010).

Отримано 27.07.12
АНОМАЛЬНАЯ

ПРОВОДИМОСТЬ В МОНОКРИСТАЛЛАХ ZnSe ПРИ РЕНТГЕНОВСКОМ ОБЛУЧЕНИИ

В.Я. Дегода, В.Т. Весна, Б.В. Кожушко, Г.П. Подуст

Р ез ю м е

Экспериментально исследована пригодность ZnSe быть детекторами для режима прямого преобразования ионизирующего излучения в электрический сигнал. Установлено, что для монокристаллического образца $\mathrm{ZnSe} n$-типа $\left(E_{d}=0,26\right.$ эВ) с удельным сопротивлением $\rho \sim 10^{9}$ Ом.см при комнатной температуре наблюдается уменьшение проводимости под воздействием рентгеновского облучения, в отличие от высокоомных монокристаллов с $\rho>10^{12}$ Ом.см. Обнаружено, что вольт-амперная характеристика (BAX) таких образцов для темновой проводимости лежит выше BAX рентгенопроводимости, причем формы кривых этих BAX заметно отличаются. Очевидно, что характер рентгенопроводимости $\mathrm{ZnSe}$, при которой генерируются свободные носители обоих знаков, существенно отличается от характера темновой проводимости, когда в образце есть только свободные электроны. Соответственно, для тока рентгенопроводимости была получена спадающая люкс-амперная характеристика (ЛАХ). До сих пор упоминание о таком нетипичном поведении упомянутых физических величин и характеристик в научно-технической литературе не встречалось. Предполагается, что такое аномальное явление может быть обусловлено неоднородной перезарядкой глубоких центров возле электрических контактов и, соответственно, появлением объемных зарядов, которые уменьшают рентгенопроводимость монокристаллического ZnSe.

\section{ANOMALOUS CONDUCTIVITY IN ZnSe SINGLE CRYSTALS BY X-RAY IRRADIATION}

\author{
V.Ya. Degoda ${ }^{1}$, V.T. Vesna ${ }^{1}$, B.V. Kozhushko ${ }^{2}$, G.P. Podust ${ }^{1}$ \\ ${ }^{1}$ Taras Shevchenko National University of Kyiv \\ (4, Prosp. Academician Glushkov, Kyiv 03022, Ukraine; \\ e-mail: degoda@univ.kiev.ua), \\ ${ }^{2}$ Institute of Physics, Nat. Acad. of Sci. of Ukraine; \\ (46, Prosp. Nauky, Kyiv 03028, Ukraine; \\ e-mail:bkozhush@iop.kiev.ua)
}

$\mathrm{S}$ u m m a r y

We study experimentally the ability of ZnSe to be detectors in the mode of direct conversion of the ionizing radiation energy in that of an electric signal. We have established that, for a monocrystalline ZnSe-sample of the $n$-type $\left(E_{d}=0.26 \mathrm{eV}\right)$ with the specific resistance $\rho \sim 10^{9} \mathrm{Ohm} \cdot \mathrm{cm}$ at room temperature, a reduction of the conductivity under the action of X-ray radiation is observed, unlike the high-resistance single crystals with $\rho>10^{12} \mathrm{Ohm} \cdot \mathrm{cm}$. We have discovered that the current-voltage characteristic (CVC) of such samples for the dark conductivity lies over the CVC with the X-ray conductivity, and the shapes of these CVC curves differ significantly. Obviously, the character of the X-ray-induced conductivity of $\mathrm{ZnSe}$, under which free carriers of both signs are 
generated, differs substantially from that of the dark conductivity, when a sample contains only free electrons. Respectively, we have obtained a decreasing lux-ampere characteristic (LAC) for the $X$-ray-induced conductivity current. Till now, the scientific and technical literature sources contained no indications of such untypical behavior of the mentioned physical quantities and characteristics. We assume that such anomalous phenomenon can be caused by the heterogeneous recharge of deep centers near electric contacts and, therefore, by the appearance of volume charges reducing the X-ray conductivity of monocrystalline ZnSe. 